\title{
Discussion on New Effective Public Service Skills for Policy Makers
}

\author{
Yuan Fang \\ School of Public Administration, Yunnan University of Finance and economics, Kunming, China, \\ 650221 \\ (Email:Yuanfang6662783@126.com)
}

\begin{abstract}
Public Service in China manifests new features. With the transformation of Values, the injection of corporate culture, the development of information technology, policy makers and civil servants are required to improve their professional level for public service. It is a new challenge for civil servants' personal ability. The author thinks excellent professional personnel engaged in public service should firstly master necessary professional skills and applies it together with performance management, human resource management and information technology. Besides, he or she should integrate ethic and moral quality into the practice of public service. Finally, he or she should have super personal leadership which is cultivated on the base of ethic and moral quality and professional skills.
\end{abstract}

KeyWords: public service, civil servants, service skills

\section{Introduction}

Great changes are taken place in the methods of public service. The traditional public service highlights governments' core position. Scholars like Mosher (1982) and Volcker (2003) think the traditional public service takes governments as centers while the present public service is not affair occupied by governments any more. In the mid-1990s, President Bill Clinton declared the end of "All-Mighty Government". Nowadays, there re not only governments, NGOs but also private sectors provide public service. Such kind of service mixed by government sectors and private sectors poses a challenge for service providers. How to enhance service skills to welcome the above mentioned challenge is a practical problem for Chinese scholars and civil servants.

\section{Research on Civil Servants' Public Service Ability of Scholars in China}

Marketization is the main drive for economic development in 30 years from Reform and Opening-up and accelerates the transformation of governments' function continually. With Chinese economy integrates into world economy, the all-mighty, examining and approving governments are transformed into governments of marketing service. A key link of establishing serving governments is the enhancement of civil servants' serving ability. Therefore, under the new economic environment and new time, how to improve civil servants' serving ability is a topic with high operability ability in a practical level.

In the present researches of China, scholars do their job in aspects such as connotation, features, composing factor of public service, and the way to enhance it. A scholar named Shen Gang pointed that public service ability including provider's skills, technique and technology which is aimed to provide high-quality public service in order to meet public needs. Scholars like Dou Zexiu and Zhao Libo think that civil servants' public service ability is the necessary subjective condition in implementing the service function and providing society with reforming service. Besides, their public service ability can manifest the competence in the course of public service. In the process of meeting needs of public service, the ability can be manifests generally as practical power and maturity such as consciousness, knowledge, intelligence, stamina and technique etc. Above all, Dou 
Zexiu and Zhao Libo think that according to the requirement of Chinese civil servants' professional quality, their ability consists of four basic factors--public service spirit, professional attainment, professional conducts and skills.

Civil servants belong to a political group which can represent public interest. It is their unshirkable responsibility to provide high-quality and satisfying public service for people. However, surveys show that there is a gap between civil servants' public service ability and people's expectation. Hence, research on improving their ability is a hot problem in academic researches. For such research, the academe holds an average view-improving civil servants' competence by reinforcing management for them. Scholars who hold this view also think that Chinese system for civil servants is not good enough. To perfect it, a fine environment including effective personnel mechanism, incentive mechanism and supervision and evaluation mechanism should be established. In such an environment, civil servants' competence of public service can be improved naturally and continually. Under a favorable environment of system, government departments can intensify various technique trainings while civil servants can increase thought and realization step by step and strengthen self-constraint in service.

Civil servants in special working locations such as in towns, grass root of countryside and SAR as well as their service competence are paid much attention by scholars.

Generally speaking, in these years, scholars have achieved a lot in the researches on civil servants' public service. However, few of them set the factors of public service from the nature and feature of new public service in it proper and objectively analyze the concrete manifestation and content. In this paper, theory of the Skill Triangle cited from American scholars James S. bowman, Jonathan P. West, Evan M. Berman and Montgomery Van Wart can offer us some ideas.

\section{The Skill Triangle in Public Service}

In today's activities of public service between public and private sectors, activities of public service can be regarded as a kind of comprehensive professional activities. Therefore, public service needs professional personnel with different backgrounds and well training. So when our Chinese civil servants carry out their tasks they should have expertise. In more and more professional practice of public service in China, civil servants' three qualities including expertise, moral character and leadership ability are of great importance.

In fig 1, the Skill Triangle shows three essential qualities and ability for Chinese civil servants during their activities in public service. With these three qualities, civil servants can accelerate their expertise to serve people with satisfaction and high-quality.

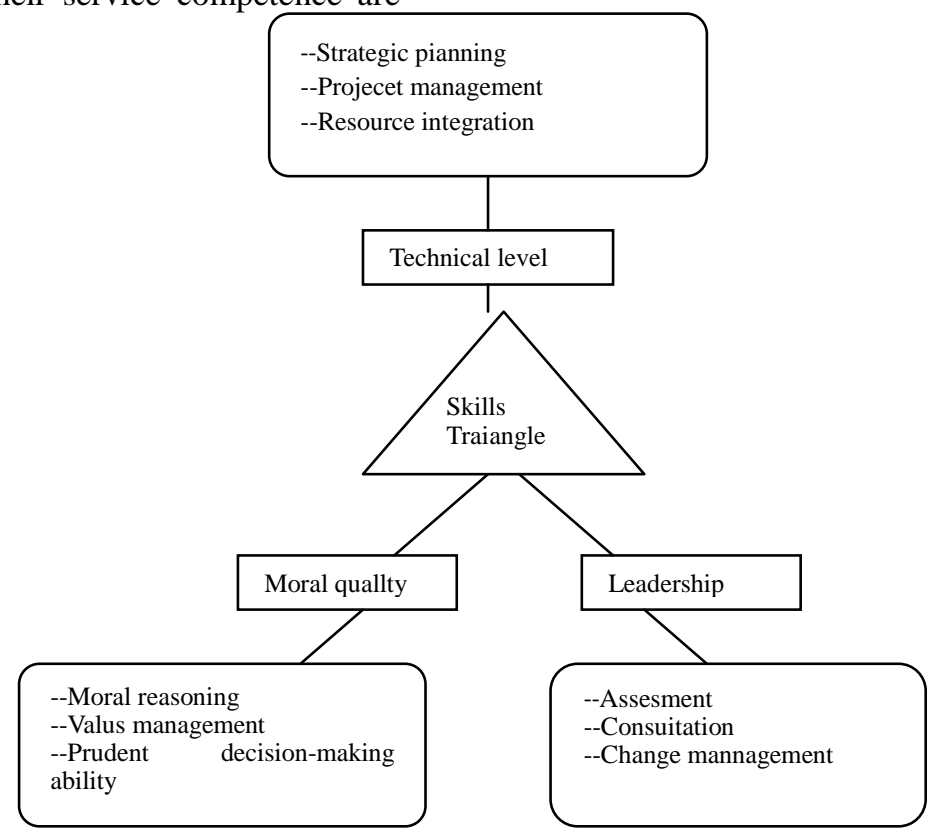

Fig 1: The Skill Triangle in Public Service[1] 


\section{The Composing and Concrete Manifestation of the Three Essential Qualities}

In Fig 1, the Skill Triangle provides an analysis frame for the questions discussed in this thesis. Today's public service requires personnel engaged in it to take the three above mentioned qualities. Although present researches of China have mentioned the three qualities, the specific content differs from one another; I will illustrate the three factors respectively.

\subsection{Expertise.}

When people choose their working fields, they depend on professional knowledge and skills. But for professional personnel of public service, besides the two above mentioned, they should also have information technology, strategic plan, project management and skills for improving performance.

4.1.1Getting to know your tasks.

People expect all managers or personnel in public departments get to know their tasks well. New-enrolled civil servants should specify their responsibilities, understand working flow and take their tasks by instruction and training. 4.1.2.Projectting and administratting items or schedules.

It is also a necessary expertise for public service. With the launch of service items from inter-departments, organizations and industries, civil servants are asked to acquire such skills - making a feasible frame and manage it. The items of competence consist of organization, programming, work definition, time-arrangement, budget, risk management, logical reasoning, technological audit, audit and evaluation. Hence, civil servants must be familiar with programming process and relevant methods. In the phase of programming, requirement should be evaluated. While in the phase of execution, they should specify responsibilities for each task and mobilize with leadership. Finally, it is the supervision and evaluation. In a word, the cooperative items between organizations and sectors will pose a bigger challenge for management skills of items and take complexity.

4.1.3. Applying new information technology.

The application of new information technology is affecting people's activities in all walks life.
The present information and technology have "joined people together to work" from different places. Furthermore, virtual interaction can happen under the circumstance that people are absent actually. New information and technology is changing people's working methods. Civil servants should master and apply the technology as soon as possible to serve the public.

4.1.4.Improving performance effectively by applying management skills.

In the long run, relevant with productivity increase, efficiency and equity is highlighted by enterprises, non-profitable organizations and public administrative departments. In public administrative departments, the latest trend of free reform is a set of management thoughts aimed for performance improvement. It can effectively accelerate the effect of public service and modulate the partnership of above mentioned three sectors by mastering and applying management thoughts and skills.

\subsection{Moral character}

The second aspect in the Skill Triangle is moral character. Under new circumstances, civil servants need not only super expertise, but also fine moral character to cope with the ethic dilemma and moral challenges in the course of organization, management and direct service. In China, there are certain laws and norms regulating civil servants behaviors of service. But as for themselves, they should strengthen self-discipline and insist on high standard requirements for their own behaviors. They should avoid scandals; spend money advisably and response people's request positively. The most important thing they should do during their direct or indirect public service is to exercise right of discretion by prudent decision. To achieve this goal, there are four categories of relative ethic competence.

4.2.1.Reasoning ability of moral principles The ethic challenges they faced require civil servants to master reasoning competence. Although common ability (interpersonal communication and observance to laws) is still mean a lot to personnel of public service, when complex decisions like "this is right and that is right" comes, reasoning competence of moral principles is significant then. Chart 1-2 states a mode of ethic decision. 


\begin{tabular}{|l|c|}
\hline \multicolumn{1}{|c|}{ Steps } & Questions \\
\hline a.collect data & $\begin{array}{c}\text { What is the fact? What are the ethic problems? What is right and what is wrong } \\
\text { under such circumstance? What should you figured out before you taking action? }\end{array}$ \\
\hline $\begin{array}{l}\text { b.make } \\
\text { substitute } \\
\text { schemes }\end{array}$ & $\begin{array}{l}\text { What can be done? What is the moral tension in all kinds of substitute } \\
\text { schemes? Are your choices opposite to organizational mission? Are these choices } \\
\text { good for intensifying relationship with people concerned on interest? Is every } \\
\text { scheme accord with personal moral code? }\end{array}$ \\
\hline c.predict results & $\begin{array}{l}\text { What the result will be? How to turn around? Have you figure out all the } \\
\text { possible results? }\end{array}$ \\
\hline $\begin{array}{l}\text { d.weigh results } \\
\text { by standard }\end{array}$ & $\begin{array}{l}\text { What should you do? How to judge this behavior by moral codes? Are all the } \\
\text { moral codes of same importance? }\end{array}$ \\
\hline $\begin{array}{l}\text { e.choices } \\
\text { behavior }\end{array}$ & $\begin{array}{l}\text { What method can be used to do this? What kind of behavior is feasible? What } \\
\text { influence will be exerted on this decision by policies and relevant laws? }\end{array}$ \\
\hline $\begin{array}{l}\text { f.evaluation on } \\
\text { behavior }\end{array}$ & $\begin{array}{l}\text { What kind of different results will come from this behavior? Is the result } \\
\text { satisfying? What will be done next? }\end{array}$ \\
\hline
\end{tabular}

Table 1 mode of six steps for ethhic reasoning

Adapted from Wartick Wood (1998); Anderson (1996); Aulisio, Arnold, and Youngner (2000)

4.2.2. Cognitive ability for clash related with ethic and morality.

It is a kind of capacity of discernment and analyzing ability for ethic problems in a specific situation. If the clash was simple, then we can cope with it with basic skills. However, if it was complicated, then advanced skills would be necessary. We can gain these skills by special training and development. At the same time, it will be good to get experts' consultation.

4.2.3. The ability for not doing affairs that the basic code of ethics is violated.

When asked to do something that the basic code of ethics is violated, you should dare to say no. It will be difficult to tell your boss that his or her commands can not be carried out because they are beyond ethics. Only one realizes his or her own core values can he or she reject to involve in wrong conducts. Some evidence shows that people who dare to do their jobs $n$ accordance with the basic code of ethics would bear pressure better from their bosses who ask them to participate in wrong conducts.

4.2.4.The ability of applying ethic theory to practice.

Ethic theory is the key to solve complicated ethic clashes. The familiarity to ethic theories, principles, rules, values and codes of conduct can be helpful to civil servants in public service for thoughtfully considering and solving thorny problems in future jobs. To improve the level for ethic decision can enhance governments' public credibility and credit of public service.

\subsection{Leadership ability}

The third aspect of the Skill Triangle is leadership ability. Personnel of public service should have new leadership ability when dealing with the transformation from bureaucracy and governments-dominant environment with public management to netlike public management environment in which public sectors, private sectors, and non-profitable organizations provide public articles and service together.

Leadership ability is consists of following aspects:

4.3.1. Leadership ability for whole situation.

It is includes budget, information system, human resource management and process scheme etc. It is really necessary for administrative organs that provide public service to have an accurate evaluating and operating system in order to command and keep consistency. Engaged in public service, civil servants needn't to be experts in budget, IT, human resource management or process scheme. But it's in badly need for them to know some basic principles of above 
mentioned fields and ways of making decision and providing service. To increase skills for evaluation and managing sharpness can improve ability for operating all matters concerned in the scope of jobs.

4.3.2. Leadership ability in human resource management.

It is a kind of leadership by which you can intercourse publicly and maintain interpersonal relationship in an increase of participation. Specifically, it is consists of promoting ability, meditating ability, coordinating ability and derived good persuasion, PRA, credibility and cooperative ability. Civil servants that engaged in public service should leave off traditional environment in which their subordinates and colleagues would execute as soon as commands came. They should consider various facts with clear tasks to cooperate with people concerned. They should raise their credibility and persuasion to love public cause.

4.3.3. Leadership ability in politics.

The leadership ability in politics such as bargaining, striving for resources, establishing critical relationship and solving clashes is significant. It is an important aspect to share your leadership authority with others. Good relationship can accelerate common view and achieve management transformation. Clashes are inevitable in high risks and shortage of resources. Civil servants' leadership can be improved by training their political insight. To become an achieved transformer, no matters you are work in your department or deal with affairs out of system; you should utilize your leadership ability in politics.

\section{Conclusion}

In today's public service, perfect and professional service requires civil servants to be armed with professional skills, moral characters and leadership ability. Super skills can guarantee them to accomplish their work of public service. And good moral characters can lead them to do right. Moreover, leadership ability is necessary for dissolving divergence between different providers of public service and promoting them to make concerted effort in public interest. If civil servants can be armed by the three above mentioned skills and persistently agree to go in for the essence of public service which aims to improve people's life with democratic values and serve others sympathetically, then they would probably provide the public with high-quality service.

\section{References}

[1] James S.Bowman, Joanthan P. West, Evan M. Berman, Montgomery Van Wart, "Competencies in Public Service," The Press of Renmin University of China,pp.21,2005.

[2] Gellerman, S. 1986. "Why 'Good' Managers Make Bad Ethical Choices. ” Harvard Business Review 64(July-August): $85-90$

[3] Holzer, G . 1997. "The Gertified Quality Manager. " Quality

Digest(February):33-38

[4] Katz, R. 1995. "The Skills of an Effective Administrator. " Harvard business Review 55: 33-42

[5] Arthur. M. B. £Rosseau. D. M. A career lexicon for 21 \# Century $[\mathrm{J}]$. The Acadery of management Executive. 1996, Vol.10 No. 4: 28-29 